\title{
La ley sobre convenciones colectivas de trabajo de 1953 y la opinión sindical en su tratamiento parlamentario. Discusiones tempranas del "modelo sindical argentino"
}

\author{
The Collective Labour Agreements Act of 1953 and the unionist's opinion in its parliamentary treatment. Early \\ discussions regarding the "Argentinian trade union model"
}

Jorge Afarian ${ }^{1}$

Universidad de Buenos Aires, Argentina

jorge.afarian@gmail.com

\author{
Sebastián Nabuel Pasarin ${ }^{2}$ \\ Universidad de Buenos Aires, Argentina \\ sebapasarin@gmail.com
}

\section{ReSUMEN:}

La ley de convenciones colectivas de trabajo de 1953 vino a regular una de las prerrogativas obreras esenciales durante el primer peronismo. Este proyecto resultó la primera oportunidad en la que el "modelo sindical argentino" fue discutido específicamente en el Congreso Nacional, al tiempo que su aprobación implicó un importante capítulo en el proceso histórico de autonomización y jerarquización del derecho del trabajo. Uno de los objetivos principales de este artículo es vincular las intervenciones parlamentarias de los diputados y senadores en el marco de la discusión del proyecto, con las conversaciones actuales en la materia. En este sentido, haremos especial hincapié en aquellos representantes de extracción sindical. Sumado a ello, vincularemos estas discusiones con el contexto histórico-jurídico de creación de esta norma. Utilizaremos como insumo principal los debates parlamentarios de aquel proyecto, convertido en ley en septiembre de 1953 con el número 14.250, que aún se encuentra vigente con mínimas modificaciones. A su vez, recurriremos a bibliografía especializada sobre la temática, mayormente artículos, obras individuales y colectivas. Concluimos que el valor de la fuente histórica directa radica no solo en que recupera voces y opiniones situadas respecto de una determinada estructura sindical y laboral que aún hoy nos rige, sino también en que resulta notable la actualidad de las posiciones teórico-políticas vertidas en este contexto, cuyos fundamentos no difieren sustancialmente casi setenta años después. Palabras clave: Proyecto de ley - Convenciones colectivas de trabajo - Diputados - Extracción sindical

Palabras Clave: Proyecto de ley, Convenciones colectivas de trabajo, Diputados, Extracción sindical.

\section{ABstract:}

The Collective Labour Agreements Act of 1953 came to regulate one of the essential workers' prerogatives of the first Peronism. This project was the first opportunity in which the "Argentinian trade union model" was discussed specifically in the National Congress. The approval of this Act implied an important chapter in the historical autonomy and hierarchization process of labour law. One of the main objectives of this article is to link the parliamentary interventions of the deputies and senators in the framework of the discussion of the project, with the current conversations in the matter. In this regard, we will place special emphasis on those representatives of trade union extraction. In addition, we will link these discussions with the historical-juridical context of the creation of this Act. Our main input will be the parliamentary discussions of that project, which became law in September 1953 with the number 14.250, which is still in force with minimal modifications. In turn, we will resort to specialized bibliography on the subject, mostly articles, individual and collective works. We conclude that the value of the direct historical source lies not only in the fact that it recovers voices and opinions regarding a trade union structure that still governs us, but at the same time the relevance of the theoretical-political positions expressed in this context is remarkable, whose foundations do not differ substantially nearly seventy years later.

KEYwORDS: Draft law, Collective Labour Agreements Act, Representatives, Union origin.

\section{INTRODUCCIÓN}

La relación entre el movimiento obrero y el peronismo es un fenómeno que, por su riqueza y diversas miradas, es objeto de numerosos abordajes y múltiples reinterpretaciones por parte de la historia, sociología, economía 
y también el derecho. La particular relación generada entre el Estado y el movimiento obrero en el período peronista propone discusiones que distan mucho de finalizar.

En estas circunstancias, observamos que el pensamiento social carece de un análisis sistematizado del conjunto normativo generado por el peronismo y su vínculo con la tendencia jurídica internacional y la circulación de saberes, lo que podría enriquecer las grandes caracterizaciones de la etapa a través de una mirada alternativa y situada.

En consonancia con estos aportes, iniciamos una serie de investigaciones vinculadas con el estudio de la producción normativa laboral del peronismo, desde los tiempos de la Secretaría de Trabajo y Previsión hasta el golpe de Estado de 1955 (Afarian y Pasarín, 2017; Pasarín, 2017), entendiendo que los procesos vinculados a la producción normativa tanto como el resultado de estos (leyes, decretos, acuerdos) constituyen elementos ineludibles para comprender el sistema de regulaciones que el peronismo intentó establecer para las relaciones capital-trabajo.

En este artículo abordamos una ley que fue presentada, discutida y sancionada en menos de una semana: la de convenciones colectivas de trabajo 14.250. Fue tratada en la Cámara de Diputados durante los días 24 y 25 de septiembre de 1953, y en la Cámara de Senadores el día 29 del mismo mes. Convertida en ley ese mismo día fue finalmente promulgada el 13 de octubre.

Si bien el trámite de esta ley fue expeditivo y su texto general contó con la aprobación de los dos bloques mayoritarios, no por ello estuvo exento de polémicas. En el desarrollo del presente trabajo nos focalizaremos principalmente en las particularidades que separaron a estos dos bloques: la Unión Cívica Radical y el Partido Justicialista, y haremos notar que se tratan de dos posiciones altamente divergentes. ${ }^{3}$

Nos detendremos con mayor detalle en las opiniones de los diputados de extracción sindical. En cuanto a los radicales, si bien los representantes obreros eran escasos en su bloque, la alusión a los principales fundamentos particulares contra la norma legal que expondremos es necesaria para una acabada comprensión del denominado "modelo sindical argentino".

Por modelo sindical argentino entendemos al conjunto de características típicas que constituyeron la condición de reconocimiento y legalización de las asociaciones sindicales, cuyos alcances pueden observarse hasta el presente. Néstor Corte (1994) señala la presencia de los siguientes rasgos: el reglamentarismo, entendido como condicionamientos del Estado para el reconocimiento de la existencia y actividad sindical, la forma asociativa basada en la profesionalidad, la unicidad sindical "promocionada”, la verticalización o concentración de la organización sindical, la potestad federativa y confederativa. A estas debe agregarse una representación o presencia gremial en los establecimientos de trabajo a través de comisiones internas o cuerpos de delegados/as. ${ }^{4}$

El autor aclara que no debe entenderse a la expresión "modelo" como un tipo ideal o paradigma en el sentido sociológico/epistemológico, sino como "caracterización descriptiva que pretende presentar los perfiles propios que singularizan su fisonomía no solo dentro del movimiento obrero latinoamericano sino también en el panorama más amplio de la realidad sindical internacional" (Corte, 1994, pp. 13-14).

Los aportes de la historia social (Benoit, 1978; Bloch, 2001; Braudel, 1999; Farge, 1991) en la que este trabajo se inscribe son de gran importancia para el análisis normativo, puesto que amplían el espectro de los actores involucrados en la creación de leyes. Se apunta en este caso a la participación de un sujeto social específico -los sindicalistas en el Congreso- y se rastrea su influencia en la creación de esta ley nuclear de las relaciones colectivas de nuestro país.

Nuestro trabajo se dividirá de la siguiente manera: en primer lugar fundamentaremos la elección de los diputados; en segundo lugar, exploraremos el contexto y los fundamentos de esta ley, mencionando las normas sobre derecho colectivo dictadas hasta aquel momento que son necesarias para comprenderla sistémicamente.

Luego nos abocaremos a la consideración del contenido normativo de la ley; describiremos las principales características del sistema de negociación y representación colectiva, y lo vincularemos con aquellos pasajes 
del debate parlamentario que estimamos pertinentes. Creemos que el análisis situado de los debates nos aportará un mejor entendimiento de aquella "doble condición" de los sindicalistas en el Congreso: como representantes obreros y como funcionarios públicos, y, por esa misma razón, parte del Estado.

Hacia el final del trabajo se reseñan las conclusiones, en las que resaltamos la importancia de conocer las fuentes primarias y rasgos del modelo sindical denominado "histórico", y sus implicancias en el sistema de relaciones colectivas vigente.

\section{LAS INTERVENCIONES DE LOS DIPUTADOS Y SENADORES}

¿Qué nos aportan las intervenciones de los diputados y senadores en el debate de la ley 14.250? Como señalamos, la ley resulta fundamental en el proceso de "maduración" del derecho del trabajo argentino. ${ }^{5} \mathrm{Al}$ mismo tiempo, es llamativo que los debates planteados en ese entonces continúen siendo los puntos nodales de las discusiones actuales. La relectura de la fuente aporta razonabilidad a las discusiones del presente y contribuye al entendimiento de nuestro sistema sindical, rescatando voces de aquella época que merecen ser recuperadas.

Como anticipáramos, centraremos nuestro análisis en las intervenciones de los dirigentes gremiales del peronismo y de la UCR, captando su visión en tanto representantes obreros. También utilizaremos intervenciones de otros legisladores que no provenían de organizaciones gremiales, las que consideramos de importancia para comprender las implicancias de la norma.

De lado del peronismo, aludiremos a las la participación de los diputados Humberto Idománico, dirigente de la Unión Obrera Metalúrgica y representante por Santa Fe; Pedro Ordóñez Pardal, dirigente de Federación de Obreros y Empleados Telefónicos de la República Argentina (FOETRA) y representante por Córdoba; José Alonso, dirigente del Sindicato Obrero de la Industria del Vestido y Afines (SOIVA) y representante por Capital Federal; Ángel Enrique Peralta, dirigente de la Federación Obrera de Empleados Vitivinícolas y Afines (FOEVA) y representante por Capital Federal, y, por último, David Diskin, dirigente del Sindicato de Empleados de Comercio (SEC) y diputado por Buenos Aires. ${ }^{6}$ Del lado de los que no pertenecen al mundo gremial, tomaremos la intervención del diputado por Santiago del Estero, Luis Pericás.

Respecto de la UCR, tomaremos las participaciones de Francisco Rabanal, dirigente de la Unión Obrera Metalúrgica y diputado por Capital Federal; Teodoro Marcó, diputado por Entre Ríos; Rodolfo Weidmann, diputado por Santa Fe; Santiago Nudelman, diputado por Capital Federal; Oscar Alende, diputado por Buenos Aires y Carlos Perette, diputado por Entre Ríos.

Prescindiremos de la intervención de los senadores ${ }^{7}$ debido a que el proyecto de ley se sancionó el mismo día que ingresó en el recinto y no intervino ningún representante por la oposición. Su trámite expeditivo no aporta significativamente a la discusión.

\section{Contexto general Del DEREcho DEL Trabajo DURANTE EL PERONISMO}

La experiencia moderna demuestra que las masas obreras mejor organizadas son, sin duda, las que pueden ser dirigidas y mejor conducidas en todos los órdenes.

(Juan Domingo Perón, Discurso en la Bolsa de Comercio, 25 de agosto de 1944)

El golpe de Estado del 4 de junio de 1943, que llevó a Pedro Pablo Ramírez a la presidencia y meses después a Juan Perón a la Secretaría de Trabajo y Previsión, significó no solo una modificación fundamental en la vida política de nuestro país, luego de varios años de gobiernos conservadores, sino que, en lo que a este trabajo interesa, implicó un cambio sin precedentes en la estructura normativa que involucra a los trabajadores y trabajadoras del país. 
Desde fines de 1943 hasta asumir como presidente en 1946, Perón fue el nexo institucional entre el movimiento obrero y el gobierno militar, y pactó con la dirección sindical distintos tipos de derechos, de los que resulta una compleja trama normativa de insuficiente sistematización. Estatutos profesionales, acuerdos colectivos, jubilaciones, sueldo anual complementario, vacaciones, vivienda, mutualidad, organización sindical, seguros, jornada, entre muchos otros, constituyen los nudos principales. El triunfo electoral de Perón "legalizará" este conjunto normativo de decretos-leyes con la sanción de la ley 12.921 del 31 de diciembre de 1946.

Una de las normas más emblemáticas a señalar es el decreto-ley 23.852 del 2 de octubre de $1945,{ }^{8}$ que regulaba las asociaciones profesionales. Aunque es conocido como el decreto de legalización de la actividad sindical, esta norma reconfigura la dinámica de lo que se conoce como relaciones colectivas de trabajo, tanto en las facultades y prerrogativas sindicales como en su relación con el Estado.

La característica principal y novedosa se observa en el otorgamiento de determinados derechos exclusivos a las asociaciones más representativas a través de la personería gremial, para promover desde el Estado la unicidad sindical. Este rasgo de origen corporativista, ${ }^{9}$ aunque moderado por la posibilidad de constituir otras asociaciones, ${ }^{10}$ perseguía la promoción de la negociación en forma centralizada, lo que otorgaba al gobierno una potestad para gestionar de forma más eficiente la conflictividad social (Elgorriaga, 2010; Fernández, 2010). Este aspecto característico del peronismo fue impulsado principalmente a través de la Secretaría de Trabajo y Previsión (Luciani, 2014).

De esta manera se abría la posibilidad de ordenar actores bajo la conducción de un solo representante y satisfacer sus expectativas a cambio de la fidelidad al proyecto político peronista. Asimismo, este sistema "formaba parte de una estrategia política para insistir en las ventajas de la sindicalización de los trabajadores y utilizar el otorgamiento o revocamiento de personerías gremiales de modo disciplinador" (Luciani, 2014, p. 6).

Este formato específico de regulación de las relaciones capital-trabajo se encuentra inmerso en el contexto de la posguerra y viene a dar respuesta al temor a la radicalización de la clase obrera. ${ }^{11}$ Aun antes de la finalización de la Segunda Guerra Mundial, esta fue una de las razones para la creación de la Secretaría de Trabajo y Previsión, como un modo de ordenar el plano de las relaciones laborales a los fines de evitar la amenaza "extranjera" comunista, socialista y anarquista durante el conflicto bélico, que se encontraba en su apogeo. Para lograr este objetivo era necesario, entre muchos aspectos analizables, contar con una representación unificada de los trabajadores y un Estado con intervención eficiente en los conflictos colectivos.

El otro gran hito del gobierno peronista que resaltamos para este recorte viene a cerrar una etapa altamente prolífera en materia de producción de normas del derecho del trabajo y de la seguridad social: la Constitución Nacional de 1949, que elevó a la máxima jerarquía jurídica numerosos derechos sociales.

En efecto, en el Capítulo III de la primera parte (correspondiente a los principios fundamentales) se concentran, entre otros, el derecho a trabajar, a una retribución justa, a la capacitación, a las condiciones dignas de trabajo, a la preservación de la salud, al bienestar, a la seguridad social, a la protección de la familia, al mejoramiento económico y a la defensa de los intereses profesionales. Este último incluía el derecho a la libre agremiación y a la participación en "otras actividades lícitas tendientes a la defensa de los intereses profesionales", dentro de las cuales podría solo inferirse el derecho de huelga, explícitamente excluido por los convencionales al momento de la votación del texto constitucional.

Como puede observarse, el período de mayor desarrollo en el que se sancionan las leyes básicas de carácter gremial abarca desde los comienzos de la actividad institucional de Perón en la Secretaría de Trabajo y Previsión, hasta la consagración constitucional de numerosos derechos fundamentales. La ley que nos ocupa fue sancionada a finales de 1953, en un momento de menor producción legal en materia de derecho del trabajo. 
En consecuencia, podría advertirse que, a diferencia de lo sucedido con otros fenómenos del trabajo que el peronismo organizó y legalizó (sindicatos, salario, sueldo anual complementario, estatutos especiales, entre otros), transcurrieron sobrados años hasta que se dictó una ley específica con directivas para el ordenamiento de la negociación colectiva y los convenios, lo que torna ineludible la pregunta sobre las razones de la espera.

Vale preguntarse: ¿Alcanzaba el mecanismo de la Secretaría de Trabajo y Previsión (luego Ministerio de Trabajo) para controlar la realidad de la negociación colectiva? ¿La ley es una deuda de la etapa inicial o una respuesta al contexto específico de 1953? ¿Cuál era la realidad en las bases gremiales obreras en los lugares de trabajo?

\section{LAS DOS CARAS DE LA NEGOCIACIÓN COLECTIVA DURANTE EL PERONISMO}

Bregamos por el derecho laboral en el ámbito de la autonomía, independencia y libertad, para que asegure a la criatura humana la protección desde la cuna hasta la tumba(Carlos Perette, Cámara de Diputados de la Nación, 25 de septiembre de 1953).

En lo que aquí nos interesa, la negociación colectiva, entendida como canal para vehiculizar el conflicto de clases en actividades o centros de producción específicos, se remonta a principios del siglo XX y se extiende luego de la crisis económica internacional de la década del 30 (Gaudio y Pilone, 1983; Campos, 2012; Luciani, 2014). Sin embargo, en esta faceta inicial se limitaba a un acuerdo entre privados, en muchos casos sin protección estatal ni extensión territorial.

Es por ello que la Secretaría de Trabajo y Previsión tuvo entre sus primigenias acciones regular administrativamente aspectos centrales de las relaciones colectivas de trabajo. Buscó entonces lograr la extensión territorial de la obligatoriedad de los acuerdos colectivos, al tiempo que crecía el protagonismo de la institución en tanto supervisora y garante de lo pactado (Luciani, 2014).

Esta regularización no implicó un modelo acabado y, aunque aportó eficiencia y profesionalidad a la gestión del conflicto social, no estuvo exenta de tensiones. Con el tiempo, las comisiones internas y las organizaciones obreras en los lugares del trabajo se constituyeron como importantes defensoras de este conjunto normativo en la práctica, lo que acrecentó su poder real en los establecimientos y excedió los límites que surgían de las instancias de dirección.

La pretensión ordenadora vino acompañada de "un considerable poder obrero en la vida diaria de las fábricas" (Basualdo, 2008, p. 8), característica que sufrió importantes modificaciones años después, durante los Congresos de la Productividad y Bienestar Social de 1954 y $1955^{12}$ (Basualdo, 2008; Lenguita y Varela, 2010; Sowter, 2016).

Sin embargo, las circunstancias en las que se considera esta norma son muy particulares, debido a que luego del segundo triunfo presidencial de Perón en 1951 se evidencia una aguda crisis económica vinculada con problemas en la balanza comercial (Campos, 2012; Kabat, 2014), lo que derivó, entre otras cuestiones, en la suspensión de la negociación colectiva por dos años, entre 1952-1954, por medio del Plan de Estabilización Económica de 1952 (Campos, 2012; Luciani, 2014).

En un contexto de puja entre el Estado y las organizaciones sindicales, atravesado por la discusión sobre la producción y la industrialización en el mencionado Congreso de la Productividad, el gobierno se acercaba a la reanudación de las negociaciones colectivas, que finalmente tendría lugar en 1954 sin un instrumento legal específico (Campos, 2012, p. 160), acompañado por un contexto de menor cohesión política en relación con otros períodos. 


\section{EL “MODELO SINDICAL” PERONISTA Y EL ANÁLISIS NORMATIVO DE LEY 14.250}

Como planteamos, si bien el entramado de normas que regulaban el modelo sindical se encontraba bastante desarrollado hacia el momento de sanción de la ley 14.250, y en paralelo la actividad sindical en sí se extendía más allá de los marcos legales -utilizando los silencios de la normativa entonces vigente para tensionar las relaciones entre el capital-trabajo (Basualdo, 2008)-, la sanción de esta ley vino a consolidar rasgos característicos del "modelo" (por ejemplo, las atribuciones exclusivas de las asociaciones con personería gremial) al tiempo que racionalizó y legalizó la actividad negociadora preexistente.

Asimismo, para la doctrina jurídica, esta norma implica el origen formal de la estructuración de la negociación colectiva en nuestro país. En términos de Mugnolo (2014), esta ley es el primer antecedente de "institucionalización trascendente" de la negociación colectiva, y configura lo que el autor identifica como modelo "histórico", cuyos alcances abarcan prácticamente la segunda mitad del siglo XX y llegan con pequeñas variaciones al presente.

Es aquí donde las intervenciones de los diputados se destacan por su riqueza, puesto que efectúan consideraciones y reflexiones respecto de los fundamentos del modelo sindical, atacando o validando sus presupuestos y orígenes. En este sentido, combinaremos el análisis de los rasgos más salientes de nuestro ordenamiento gremial, junto con las intervenciones de los diputados que abordan la temática específica. Haremos alusión a los alcances de esta ley y a los debates en la actualidad.

\section{Los SUJETOS DE LA NEGOCIACIÓN COLECTIVA Y EL SISTEMA DE LA PERSONERÍA GREMIAL ${ }^{13}$}

Resulta difícil pensar un sistema de negociación colectiva que prescinda de una determinación y regulación específica de los sujetos. En efecto, el mecanismo para generar obligaciones entre los representantes del capital y del trabajo comienza por seleccionar y legitimar los interlocutores válidos y, habitualmente, asignar un sistema de jerarquías a algunos por sobre otros, por lo que cobra relevancia el concepto de representatividad. ${ }^{14}$ En otras palabras, regulación de asociaciones sindicales y regulación de negociación colectiva se encuentran inescindiblemente vinculadas y son las dos caras de una misma moneda.

El primer elemento a destacar en la ley 14.250 es el reconocimiento y consolidación del sistema de personería gremial (artículo 1). En efecto, al determinar los sujetos legitimados para la negociación colectiva vemos que, por el sector trabajador solo pueden celebrar convenciones colectivas de trabajo aquellas asociaciones profesionales con personería gremial. ${ }^{15}$ Tal circunstancia reafirma la vigencia del sistema existente en el decreto-ley 23.852/45 de asociaciones profesionales, que contribye con la centralización y verticalización del mundo sindical, y tiene como resultado organizaciones de trabajadores de alcance nacional, con capacidad federativa y confederativa.

Esta última norma, que cuenta con más de sesenta artículos, instaura derechos fundamentales como el derecho de libre asociación gremial. Define qué se entiende por sindicato, y diferencia entre organizaciones "simplemente inscriptas" y las que poseen personería gremial, y los derechos que les caben a cada una de ellas. Por otro lado, afirma la independencia de los sindicatos respecto del Estado y las organizaciones de empleadores, los cuales no podían intervenirlos o subsidiarlos directa o indirectamente. A partir del artículo 8 podemos hallar las condiciones específicas de los sindicatos para adquirir la personería gremial y la forma específica que se exigía.

El artículo 33 establece los derechos exclusivos de la personería gremial, como la posibilidad de negociar colectivamente y firmar convenios colectivos de trabajo, la defensa ante el Estado y empleadores de los intereses profesionales e individuales de los trabajadores, la participación "circunstancial" en actividades políticas, entre otras. 
Más adelante, en el artículo 37, se establece una preferencia por parte del Estado y concesionarias de servicios públicos u obras públicas para la contratación de trabajadores afiliados a asociaciones reconocidas por el Estado.

El artículo 42 alude a las razones para la suspensión de la personería gremial, entre las que se encuentra no dar cumplimiento a disposiciones dictadas por autoridad competente "en ejercicio de sus facultades legales", acápite por demás amplio y que daba lugar a numerosas intromisiones estatales. La suspensión de la personería podía apelarse solo ante el Poder Ejecutivo. Esto implica que el recurso recae sobre el mismo poder que suspende la facultad otorgada, lo que en principio atentaría contra el derecho de defensa y control ante un tercero que dirimiera el conflicto.

Para comprender el diseño que instaura la norma, además de la normativa ya señalada, debe mencionarse la no ratificación, en aquel momento, de los convenios 87 y 98 de la OIT, ${ }^{16}$ así como también la posibilidad legal de criminalizar las huelgas a través del decreto-ley 536/45. ${ }^{17}$

El modelo de personería gremial fue defendido por los diputados obreros peronistas en los debates del proyecto de ley 14.250. Al respecto, el diputado Pericás consideró que la invalidez de los convenios firmados por asociaciones sin personería gremial se encuentra justificada, puesto que "semejante libertad de contratación" fomentaría el desorden y la dilatación en la resolución de los conflictos colectivos (Diario de Sesiones de la Cámara de Diputados, 1953, p. 1780). A su vez, los acuerdos numerosos podrían originar situaciones fraudulentas por parte de los empleadores, que podrían recurrir a sindicatos con escasa representación y así imponer sus cláusulas limitativas de derechos.

El siguiente diputado gremialista, José Alonso, anticipando que los representantes de la oposición "no tienen autoridad para dar lecciones de sindicalismo” (Diario de Sesiones de la Cámara de Diputados, 1953, p. 1782), expresa que el peronismo da con esta ley un nuevo salto en la protección al trabajador.

Sobre la personería gremial, defiende su "ratificación" en la XXXIV reunión de la Conferencia Internacional del Trabajo (OIT), a través de la recomendación $n^{\circ} 91$, en la que se afirma la expresión de "contrato colectivo" como un acuerdo entre un empleador o grupo de empleadores u organizaciones, y organizaciones representativas de trabajadores. Para Alonso, el vocablo representativo alude a la personería gremial, lo que le otorga autoridad ejecutiva a la convención colectiva.

El diputado Peralta, a su tiempo, considera que la unicidad sindical y un movimiento obrero organizado a través de sindicatos con personería gremial son necesarios. Lo que realmente importa es que el gremio cumpla, se rija por la voluntad de la mayoría, y que todos los obreros tengan la oportunidad de emitir su opinión. ${ }^{18}$ Concretamente, la unidad obrera vigoriza al movimiento y le otorga mayor peso en las negociaciones. Por el contrario, colectivos "dispersos" o "plurales" redundarían en un debilitamiento innecesario.

Como se observa, los dirigentes gremiales defienden a ultranza el modelo de derechos exclusivos basado en la representatividad, enfatizando las ventajas de la unión de los obreros en grandes asociaciones por sobre otros modelos que habilitan el surgimiento de núcleos identificados como "dispersos". Solo en el caso del diputado Peralta se señala la importancia de canales de opinión de "todos los obreros" en el interior de los sindicatos.

Del otro lado, la intervención de la Unión Cívica Radical en estas sesiones se centrará en criticar aspectos particulares del proyecto, los que estarán fundamentalmente dirigidos al modelo de personería gremial y a las consecuencias que conlleva.

El diputado Rabanal, dirigente de la UOM, cita el discurso de Perón en la Bolsa de Comercio en 1944, en el que se explicita la intención de un sindicalismo organizado, vertical y dirigido por el Estado, conducido para apuntalar la política del régimen de aquel entonces. Considera que el decreto-ley 23.852 fue claramente en esta dirección; diferenciaba entre obreros adictos y opositores al gobierno, y atentaba contra la libertad sindical de los trabajadores. ${ }^{19}$

El diputado Marcó, si bien acepta la ley en su generalidad, señalando que resulta necesaria para un mayor acceso a derechos por parte de los trabajadores, conceptualiza la personería gremial como una negación de 
la libertad sindical, dado que se impone una afiliación obligatoria de los trabajadores a aquellos sindicatos, y se desecha a los que no cuentan con personería. Considera que la norma es similar al régimen corporativo fascista italiano, que tiende al sindicalismo como único, obligatorio y adicto al Estado.

En igual sentido, pero con mayor intensidad, se inscribe el discurso del diputado Weidmann. Afirma que la OIT, en su XXXIII reunión, se proclama a favor de una libertad amplia de negociación, admitiendo una o varias organizaciones de trabajadores y señalando las contradicciones existentes entre el sistema argentino y los criterios de la Organización Internacional del Trabajo.

Alude a la clara preferencia estatal por un sindicalismo único, estableciendo prerrogativas específicas y exclusivas para los más representativos, y, al mismo tiempo, limitando seriamente la posibilidad de desplazamiento de aquellas hacia otros sindicatos.

Refiere dos circunstancias de importancia: el decreto-ley 23.852 implica un avance sobre la libertad sindical e importa la estatización y burocratización de las organizaciones obreras. Advierte que el derecho de reunión depende de la concesión discrecional del Ministerio de Trabajo (conforme el artículo 21). Por otro lado, señala que se permite la intervención en el campo político a través del artículo 33, habilitando la actuación continua y exclusiva del sindicato como partido político.

A su tiempo, el diputado Nudelman reitera la tendencia totalitaria del proyecto, con sindicatos al servicio del Estado, aniquilándose al individuo, considerado un simple engranaje de la burocracia estatal. Desde su visión, el Estado es el pretexto del despotismo. Al igual que sus colegas, basa sus fundamentaciones en citas a teóricos del derecho del trabajo. Siguiendo a Deveali (1952), por ejemplo, expresa que el hecho al reconocimiento de la personería gremial no puede llevar necesariamente a la exclusión de otras asociaciones gremiales constituidas por el mismo gremio de trabajadores. Solo a través de esa forma se concilia la unicidad con las categorías de libertad de asociación y libertad sindical.

El siguiente diputado, Oscar Alende, en concordancia con los demás diputados de la UCR, anticipa que la minoría votará a favor de la ley en general, pero que está en contra de los totalitarismos y a favor de una democracia social y económica integral. Al igual que Rabanal y Nudelman, cita el discurso de Perón en la Bolsa de Comercio, en el que expresaba una necesidad de dirección y conducción de las masas obreras por parte del Estado.

El último diputado por la oposición que citaremos es Carlos Perette. En primer lugar expresa que la defensa de los derechos laborales no comporta la renuncia a la defensa y a la protección de los derechos humanos, basamento del bienestar de los trabajadores. Es decir, si bien el bloque radical está a favor de la sanción en general de la ley, no acuerda con una norma que fomente el corporativismo. A través de una cita al político socialista Américo Ghioldi afirma que "sin libertad caemos en el totalitarismo y caemos en el comunismo" (Diario de Sesiones de la Cámara de Diputados, 1953, p. 1789). El proyecto, según el diputado, ataca la libertad sindical, la libertad de agremiación, y derechos fundamentales como el de huelga (particularmente menciona el decreto-ley 536 de 1945).

Al legitimar a estos actores como los únicos facultados para negociar y conceder el sistema de prerrogativas exclusivas desarrollado, consecuentemente se ejerce una fuerte influencia en la negociación colectiva. En principio, se desincentivan los acuerdos por empresa, lo que promueve la centralización por actividad con alcance nacional.

Resulta llamativo que luego de más de seis décadas de la sanción de la ley los debates y cuestionamientos giran fundamentalmente en torno al mismo punto. La vigencia de estas discusiones en la actualidad jurídica nacional e internacional es manifiesta.

En este sentido, la opinión de la Organización Internacional del Trabajo sobre la ley actual de asociaciones sindicales 23.551 y sus reglamentaciones ${ }^{20}$ es de gran utilidad. Al respecto, uno de sus órganos principales, la Comisión de Expertos en Aplicación de Convenios y Recomendaciones, viene reiterando con fluctuante intensidad recomendaciones que buscan la adecuación del sistema argentino a los principios de los convenios internacionales. 
Si bien, como señala Recalde (2015), la OIT acepta el sistema de personería gremial al plantear que el reconocimiento de sindicatos más representativos por la legislación no es estrictamente contrario a la libertad sindical, también fija ciertos límites a estos privilegios, que no deben exceder el hecho de ser una prioridad -y no la exclusividad- en materia de representación en las negociaciones colectivas, en la consulta por las autoridades, y en la designación de los delegados ante los organismos internacionales. ${ }^{21}$

Relacionado con ello, la Corte Suprema de Justicia de la Nación intervino en este debate desde el año 2008 con una serie de fallos en la materia, los cuales resultan transcendentes porque declaran la inconstitucionalidad de diversos artículos de la ley 23.551, particularmente en lo que hace a la tutela sindical. Estos fallos, sin embargo, no cuestionan el sistema en su conjunto. ${ }^{22}$

\section{El intervencionismo y las facultades reservadas al Poder Ejecutivo}

Otro rasgo de este sistema, acentuado a partir de la ley de analizada, constituye el fuerte intervencionismo del Poder Ejecutivo a través del Ministerio de Trabajo. En efecto, el Ministerio tiene a su cargo homologar (art. 3), publicar y registrar el convenio colectivo (art. 4), integrar y legitimar a la parte empleadora cuando no existiere (art. 9), extender territorialmente la obligatoriedad del convenio (art. 10), reunir a las partes antes del vencimiento del convenio (art. 12), ser instancia de apelación de las resoluciones que tomen las comisiones paritarias consagradas en el apartado II (art. 17), ser autoridad de aplicación y garante del cumplimiento de las convenciones firmadas con facultad sancionatoria (art. 13). ${ }^{23}$

Como puede observarse, en el diseño planteado el Poder Ejecutivo posee un rol protagónico, hecho que modifica el ámbito de la negociación, teóricamente planteada como un acuerdo entre privados, al involucrar inevitablemente al Ministerio de Trabajo. Apela para ello al interés público y le da amplitud "universal" a los acuerdos.

En efecto en la nota que acompaña el proyecto de ley, suscripta por Perón, podemos extraer las perspectivas de regulación:

Con sobrada razón se ha dicho de ella [la convención colectiva] que tiene cuerpo de contrato y alma de ley: lo primero porque substancialmente descansa en un acuerdo de voluntades; lo segundo, porque por su importancia real y por su aplicación aun a las personas que no han intervenido directa o indirectamente en su celebración, supera los límite del contrato de derecho civil y asimila aquel acuerdo a la ley (Diario de Sesiones de la Cámara de Diputados, 1953, p. 1682).

Sin embargo, no debe perderse de vista que, al menos para la dirigencia obrera peronista en el Congreso, la intervención del Estado en las relaciones entre capital y trabajo era señalada como un elemento progresivo. En efecto, el diputado Ordóñez Pardal estima que la "revolución nacional peronista" modificó la sociedad argentina, encauzando las relaciones colectivas a través del imperio de la justicia. Asimismo, las relaciones de solidaridad colectiva obrera otorgaron un basamento a la organización sindical moderna, pero no fue sino hasta el advenimiento del peronismo que se orientó positivamente el conflicto, acercando a las partes para conciliar diferendos y aspiraciones disímiles. ${ }^{24}$

Concordantemente, el legislador Idománico expresa que a partir de la llegada del peronismo, y especialmente a través de la reforma constitucional de 1949, se comienza a dotar al contrato laboral de una carga social y colectiva como medio de asegurar y adquirir derechos esenciales por medio del Estado.

El diputado Diskin, a su tiempo, esboza una conceptualización más “clasista”. En primer lugar se encarga de diferenciar entre los regímenes totalitarios, el sindicalismo fascista o comunista y el sindicalismo argentino. Considera que en estos modelos totalitarios el sindicalismo "no es más que un instrumento del Estado, creado por el Estado, dirigido por el Estado y al servicio del Estado" (Diario de Sesiones de la Cámara de Diputados, 1953, p. 1814). Al momento de caracterizar el movimiento obrero argentino indica que este es "libre y democrático" y su coincidencia con el peronismo es circunstancial, basada en el trabajo conjunto por 
una expresión de carácter nacional y emancipadora. Es decir, hay una coincidencia en la doctrina y en los propósitos, que marchan por caminos paralelos y persiguen los mismos principios e ideales.

La estatización del fenómeno de la negociación colectiva, además de perseguir los fines mencionados, creó un sistema por el cual el producto del proceso de negociación podía ser extendido territorialmente y aplicado a todos los miembros de una actividad determinada. Para ello debía pasar por un filtro técnico-político en cabeza del Ministerio de Trabajo, que continúa vigente en la actualidad: la homologación. De todos los rasgos mencionados, el protagonismo del Estado se observa más nítidamente en este proceso.

Respecto de este instituto y su fundamento, nuevamente el diputado Idománico expresa que la homologación del acuerdo colectivo, correctamente a cargo del Ministerio de Trabajo, otorgaría al convenio "verdadera fuerza de aplicación", y resalta que esta dependencia del Poder Ejecutivo "representa en este sentido al pueblo trabajador de la Nación” (Diario de Sesiones de la Cámara de Diputados, 1953, p. 1765).

El sistema de homologación involucra fundamentalmente los artículos 6 al 9 de la ley. En el artículo sexto se consagra una técnica legal por la cual se analizan los diversos "institutos" negociados (jornada de trabajo, vacaciones, entre otros) en contraste con la legislación vigente en la materia. Esto procura que el campo cedido a los privados no vulnere los pisos mínimos de protección del ordenamiento público.

$\mathrm{Al}$ mismo tiempo, se garantiza que si el convenio (voluntad colectiva) ubica a los trabajadores en una situación jurídica inferior a aquel piso legal (orden público laboral) en determinada institución laboral, estos derechos no pierden validez ante el acuerdo. Por el contrario, son reemplazados por las cláusulas legales conocidas como "orden público laboral", sin perder vigencia el resto del convenio. ${ }^{25}$ En otras palabras, la voluntad colectiva no puede ir más allá de los "pisos" de derechos establecidos por el orden público laboral, solo puede ser utilizada como mecanismo para mejorar los derechos mínimos de los trabajadores. ${ }^{26}$

Además este límite fuertemente progresivo para la clase trabajadora se consagra otro, que resulta más complejo. El control del Poder Ejecutivo basado en el "interés general". La vaguedad del término elegido no es casual; existe un amplio margen de discrecionalidad en cabeza del Poder Ejecutivo para determinar en qué momento se afecta ese "interés general". Por ejemplo, podría aducirse que un aumento salarial determinado afectará el interés general, dado que un porcentaje de aumento para un sector se trasladaría luego a los costos de un producto de consumo masivo. ${ }^{27}$

El artículo séptimo establece la pauta de relación entre las fuentes del derecho colectivo y los contratos individuales del trabajo, indicando que si un trabajador logra en forma individual mejores condiciones que las que establece el convenio podrá gozarlas, pero no de manera inversa.

El artículo octavo legisla los efectos de la homologación de la convención. Es lo que la doctrina jurídica conoce como el efecto erga omnes. Esto deriva en la extensión de la convención a toda la categoría profesional (grupo específico de trabajadores) que representa la asociación sindical en su ámbito territorial, con prescindencia de la afiliación de los representados a la entidad sindical firmante. Asimismo, establece un margen para incluir "beneficios especiales" para la asociación gremial firmante, lo que excede su rol de representación y la constituye como un actor plausible de preferencias y derechos exclusivos.

\section{CUOTA DE SOLIDARIDAD Y ULTRAACTIVIDAD DEL CONVENIO COLECTIVO}

La cuota de solidaridad, considerada en términos generales como un derecho exclusivo para el sindicato con personería gremial, consiste en la posibilidad de exigir a los obreros beneficiados por el convenio colectivo no afiliados a dicho sindicato una contribución por la "gestión" del mismo. Si bien su tratamiento por los diputados, en comparación con la personería gremial y la intervención del Estado fue más escueto, una breve alusión tanto a los aspectos positivos como negativos contribuirá a resumir el estado de la cuestión en aquel momento. 
$\mathrm{Al}$ respecto, en el debate parlamentario hallamos dos opiniones bien diferenciadas: del lado peronista, José Alonso justifica la contribución de solidaridad, puesto que "no es posible que la parte beneficiada acepte fraccionadamente lo relativo a los salarios o los beneficios y, por el otro lado, rehúya la responsabilidad frente a la entidad" (Diario de Sesiones de la Cámara de Diputados, 1953, pp. 1795 y 1816).

En la misma sintonía, el diputado Diskin afirma la constitucionalidad de las contribuciones solidarias, bajo la lógica de que el aprovechamiento de las mejoras del convenio por parte de los trabajadores no afiliados otorga el derecho al gremio a exigir la colaboración en su sostenimiento. Expresa que las puertas del sindicato siempre se encuentran abiertas a los trabajadores aunque estos elijan no afiliarse. Al mismo tiempo el trabajador cuenta con "el derecho de exigirle que contribuya al sostenimiento sindical" (Diario de Sesiones de la Cámara de Diputados, 1953, p. 1815).

Del lado de la oposición, el diputado Marcó considera que dicha colaboración establece una "dictadura sindical" a través de los aportes obligatorios de los no afiliados, quienes no desean contribuir a un gremio contrario a sus opiniones y sentimientos. Ello se agudiza con el otorgamiento de privilegios en el acceso al empleo para los obreros afiliados al sindicato con personería gremial. Sobre el final del debate, y en nombre del bloque radical, el diputado Perette impugna especialmente la cuota de solidaridad del proyecto de ley.

Actualmente, los principales cuestionamientos al respecto de este instituto no están basados estrictamente en la discusión sobre su legalidad/legitimidad. No obstante, existen debates vinculados con reconocerla como un medio apropiado respecto a los fines que busca reparar. Esto especialmente cuando, como sucede en Argentina, los convenios colectivos de trabajo se prorrogan sobre la base de lo que se conoce como ultraactividad y no podemos pensar en una negociación colectiva que vaya mucho más allá de una actualización salarial. ${ }^{28}$ La cuestión de la ultraactividad tampoco fue considerada especialmente por los representantes en el Congreso.

\section{Conclusiones}

La ley 14.250 culmina la legalización básica del modelo sindical peronista. En su texto y en los debates que precedieron a su sanción se observan las principales argumentaciones a favor y en contra de esta normativa. La pretenciosa tarea de "estatizar" y "ordenar" el conflicto social, en tanto objetivo político del peronismo, se visualiza cristalinamente en esta ley.

Del análisis de los debates se desprende la necesidad de contar con una norma de este tipo en tanto parámetro interpretativo para los jueces, como así también a modo de reconocimiento -tardío- de un derecho obrero ya presente en el ámbito internacional y comparado. A estas razones se suma la necesidad de recentralizar la negociación colectiva en un período de crisis en el cual, ante la suspensión de las rondas de negociación hasta 1954, aumentaba el poder obrero real en las fábricas y lugares de trabajo, a la vez que se abrían las puertas para el cuestionamiento de las direcciones sindicales.

A pesar de la disociación que se percibe entre bases y dirección obrera en este contexto de crisis y parálisis de la negociación colectiva, el poder político de los trabajadores había alcanzado niveles significativos. No solo dan cuenta de ello las intervenciones reseñadas en este trabajo sino también la fuerte integración de dirigentes sindicales en la estructura del Poder Ejecutivo (ministerios, secretarías, direcciones, entre otras). Este rasgo, presente desde los primeros años de la presidencia de Perón, alcanzaba para la época un amplio desarrollo; no se trataba ya de casos paradigmáticos o aislados como los de Ángel Borlenghi y José María Freire, sino que para ese entonces había un gran número de diputados obreros que integraban el Congreso de la Nación.

Esta realidad invitó no solo a controlar la gestación y funcionamiento de las asociaciones gremiales esquema sobre el cual ya pesaban cuestionamientos-, sino a propugnar una mayor mediación e intervención en el conflicto a través de mecanismos de regulación. Para la dirección sindical, también significaba una herramienta de reafirmación de su conducción, que buscaba limitar el poder de los delegados y comités de fábrica. 
En un contexto atravesado por sensibles cambios, y en atención a los fines productivistas motivados por la crisis, debía avanzarse en herramientas tendientes a mediar en el conflicto en los lugares de trabajo, regularlo y plantear los alcances de los acuerdos colectivos, cuestión que se justifica aún más en el Congreso de la Productividad, poco antes del golpe de Estado de 1955.

Esta forma específica de normativización de los procesos de negociación colectiva, según entendemos, persigue estos fines al tiempo que condensa los rasgos más salientes del modelo peronista garantizado en disposiciones anteriores.

Por otro lado, como expresáramos, es la primera vez que se discute orgánicamente en el Parlamento la negociación colectiva. $\mathrm{Al}$ abordar aspectos como la personería gremial, la homologación, la ultraactividad, la cuota de solidaridad, y el resto de los institutos mencionados, se revaloriza la fuente, entendiéndola como un escrutinio de la etapa en cabeza de los representantes legislativos (gremiales o no) de los partidos mayoritarios.

Esto no constituye un rasgo menor, puesto que inaugura o completa posturas que se mantienen aún hasta nuestros días en el campo jurídico y político. Tal extremo se evidencia no solo en los márgenes del debate académico sino también en las decisiones de la Corte Suprema de Justicia de la Nación y en las opiniones de la Organización Internacional del Trabajo. Así, la claridad en el manejo de la fuente originaria puede implicar un aporte significativo para el diálogo institucional sobre el tema.

El modelo de derechos exclusivos para el sindicato más representativo, por sobre otros reconocidos, aunque impugnado por colectivos de trabajadores, académicos y fallos judiciales -especialmente en los años noventa y la primera década del siglo XXI- no ha variado significativamente como para afirmar su extinción. Muy por el contrario, su legitimidad se apoya principalmente en la defensa del modelo que realizan las representaciones sindicales mayoritarias. Observar estos argumentos en las intervenciones de los diputados en 1953 ofrece un parámetro acerca del arraigo de estas posiciones políticas.

En este sentido, una de las principales decisiones posteriores al golpe de Estado de 1955 fue la desarticulación del sistema de convenciones y representatividad colectivas. No solo se anularon numerosas normas (comenzando por la Constitución de 1949), sino que se ratificaron convenios internacionales "amplios" de la OIT, buscando flexibilizar aspectos centrales de la concepción peronista.

También, a través de la reforma constitucional de 1957, se agregó el artículo 14 bis, que otorgaba a los gremios (como entes conceptualmente más abarcativos que los sindicatos) el derecho de negociar colectivamente, con el objetivo de desarticular la idea de grandes entidades con personería gremial como las únicas legitimadas para aquello.

Luego de la restauración democrática de 1983, las reformas llevadas a cabo tendieron a profundizar o restablecer los rasgos originarios. La ley 23.546, de negociación colectiva de 1988, la ley 23.551 de asociaciones sindicales del mismo año, o la ley 24.877, de "reordenamiento laboral" de 2004 son algunos ejemplos.

Por el contrario, sí puede evidenciarse una importante modificación en la composición de las relaciones de trabajo, con un sindicalismo vertical debilitado, mayor distancia con las bases y un escaso número de negociaciones colectivas por actividad, especialmente en los años noventa (De La Garza Toledo, 2005; Etchemendy y Collier, 2008; Haidar, 2009). Aquellas circunstancias propiciaron el protagonismo de los movimientos sociales y organizaciones de base, que desde la mitad de aquella década nuclearon gran parte de los reclamos sociales.

Estas experiencias gremiales propugnan la democratización interna de los sindicatos y un modelo de pluralidad y libertad sindical que flexibilice los privilegios exclusivos de las entidades más representativas. Durante la década del noventa, la Central de Trabajadores de Argentina fue uno de los ejemplos más característicos.

Con esta breve reseña buscamos remarcar que la fuente analizada atraviesa puntos nodales y peliagudos de la conversación jurídica sobre el trabajo y sus representantes en Argentina. ${ }^{29}$ De este modo, creemos que los aportes históricos, como el que pretendemos en este texto, pueden contribuir a una mirada menos circunstancial de la problemática. 
Por último, remarcamos que el sistema actualmente vigente encuentra fuertes similitudes con el "histórico" que aquí se repasa, lo que evidencia la dificultad para incorporar y reconocer los fenómenos cambiantes de la realidad actual. No podemos menos que señalar este punto con acucia ante el incesante aumento de la precarización laboral y el desempleo, con la consiguiente exclusión de otros colectivos representativos de estas realidades, que son cruciales en la lucha contra el actual desenvolvimiento productivo capitalista.

\section{Bibliografía}

Abós, A. (1989). El modelo sindical argentino: autonomia y Estado. Buenos Aires: Fundación Friedrich Ebert.

Afarian, J., y Pasarín, S. (2017). Sindicalistas y Estado: un análisis comparativo de trayectorias e instituciones durante el peronismo clásico (1945-1955) (Ponencia presentada en XVI Jornadas Interescuelas de Historia), Universidad Nacional de Mar del Plata, Buenos Aires.

Altamirano, C. (2007). Bajo el signo de las masas (1943-1973). Biblioteca del Pensamiento Argentino. Buenos Aires: Editorial EMECÉ.

Basualdo, V. (2008). Los delegados y las comisiones internas en la historia argentina: una mirada de largo plazo, desde sus orígenes hasta la actualidad. Buenos Aires: DGB Bildungswerk/Friedrich Ebert Stiftung/CTA/Fetia. Recuperado de https://lostrabajadoresenargentina.files.wordpress.com/2013/09/basualdo-2010.pdf

Barattini, M. R. (2015). ¿Modelos sindicales en disputa? La cuestión de la legalidad y la representación en las experiencias sindicales de las últimas dos décadas en Argentina y Brasil. Buenos Aires: Editorial CLACSO.

Basualdo, V. (2010). Labor and structural change: Shop-floor organization and militancy in Argentine industrial factories (1943-1983) (Tesis de doctorado), Universidad de Columbia, Nueva York.

Benoit, J. (1978). Hacer la historia social de Latinoamérica. Revista Dialéctica, 3(5), 9-25.

Ber Gelbard, J. (1955). El acto inaugural del Congreso Nacional de la Productividad y Bienestar Social. Hechos e Ideas, 131.

Bloch, M. (2001). Apología para la historia o el oficio del historiador. México: FCE.

Braudel, F. (1999). La historia y las ciencias sociales. Madrid: Alianza Editorial.

Campos, L. (2012). Estructura sindical, negociación colectiva y relaciones de fuerza. Un análisis de la trayectoria de las formas de organización y acción sindical en el largo plazo, Argentina 1945-2001. (Tesis de doctorado, FLACSO). Recuperada de http://www.relats.org/documentos/HIST.Campos.pdf

Corte, N. (1994). El modelo sindical argentino. Régimen legal de las asociaciones sindicales. Santa Fe: Rubinzal-Culzoni Editores.

De La Garza Toledo, E. (comp.) (2005). Sindicatos y nuevos movimientos sociales en América Latina. Buenos Aires: CLACSO. Recuperado de http://biblioteca.clacso.edu.ar/clacso/gt/20101109023754/garza6.pdf

Deveali, M. (1952). Curso de Derecho Sindical y de la Previsión Social. Buenos Aires: Editorial Zavalía.

Elgorriaga, L. (2010). Los origenes del modelo sindical argentino (1896-1945). Relaciones Laborales. Buenos Aires: BdeF Editores.

Elías, J. (2007). Procedimiento de la negociación. En M. Ackerman (dir.) y D. Tosca (coord.), Tratado de Derecho del Trabajo. Santa Fe: Rubinzal-Culzoni Editores.

Etchemendy, S., y Collier, R. (2008). Golpeados pero de pie. Resurgimiento sindical y neocorporativismo segmentado en Argentina (2003-2007). POSTData. Revista de Reflexión y Análisis Politico, 13, 145-192. Recuperado de ht tp://www.scielo.org.ar/pdf/postdata/n13/n13a07.pdf

Farge, A. (1991). La atracción del archivo. Valencia: Edicions Alfons El Magnánim.

Fernández, A. (2010). El sindicalismo argentino frente al bicentenario: una reseña histórica. Revista del Trabajo, 8 , 83-103. Recuperado de http://hdl.handle.net/11336/17835

Gaudio, R., y Pilone, J. (1983). El desarrollo de la negociación colectiva durante la etapa de modernización industrial en la Argentina, 1935-1943. Desarrollo Económico, 23(90), 255-286. 
Goldin, A. (dir.), y Alimenti, J. (coord.) (2013). Curso de Derecho del Trabajo y la Seguridad Social. Buenos Aires: Ed. La Ley.

Haidar, J. (2009). Revitalización sindical en argentina. ¿Sindicalismo de movimiento social o neocorporativismo segmentado? Actas del XXVII Congreso de la Asociación Latinoamericana de Sociología. VIIIJornadas de Sociología de la Universidad de Buenos Aires, Argentina. Recuperado de http://cdsa.aacademica.org/000-062

Herrera, C. M. (2014). En los orígenes del constitucionalismo social argentino: discursos en torno a la constitución de 1949. Revista Historia Constitucional, 15, 391-414.DOI http://dx.doi.org/10.17811/hc.v0i15.407.g366

Kabat, M. (2014). Evolución de la negociación colectiva en las industrias del cuero en la Argentina (1954 a la actualidad). Revista Trabajo y Sociedad, 22, 493-509. Recuperado de http://www.scielo.org.ar/pdf/tys/n22/n2 2a28.pdf

Lenguita, P., y Varela, P. (2010). Una reflexión sobre el rol de las comisiones internas en el sindicalismo argentino. En C. Figari, P. Lenguita y J. Montes Cató, (comps.), El movimiento obrero en disputa. La organización colectiva de los trabajadores, su lucha y resistencia en la Argentina del siglo XX. Buenos Aires: CICCUS.

Luciani, M. P. (2014). El Estado peronista frente a las negociaciones colectivas: de las nuevas herramientas institucionales a la legalización de las convenciones colectivas. Revista Nacional de la Facultad de Ciencias Sociales, 34(49), 1-15. Recuperado de http://www.revistas.una.ac.cr/index.php/abra/article/view/6246/6237

Mugnolo, J. P. (2014). Estructura de la negociación colectiva. Buenos Aires: EDIAR.

Mugnolo, J. P. (2005). Las cuotas de solidaridad ante el necesario financiamiento de las organizaciones sindicales. Revista LEXIS NEXIS: Laboral y Seguridad Social, 3.

Organización Internacional del Trabajo (Comisión de Expertos en Aplicación de Convenios y Recomendaciones) (1994). Libertad sindical y negociación colectiva. Ginebra: Oficina Internacional del Trabajo.

Palacio J. M. (2013). El peronismo y la invención de la justicia del trabajo en la Argentina. Revista Nuevo, Mundo Mundos Nuevos, Open Edition Journals. Recuperado de http://journals.openedition.org/nuevomundo/65765

Palacio, J. M. (2018). La justicia peronista. La construcción de un nuevo orden legal en Argentina. Buenos Aires: Siglo Veintiuno Editores.

Pasarín, S. (2017). El decreto 33.302 de 1945: prototipo del derecho del trabajo en la Argentina. Actas de las $V$ Jornadas de Jóvenes investigadoras/es en derecho y ciencias sociales del Instituto de Investigaciones "Ambrosio L. Gioja, Argentina. Recuperado de https://jornadasdejovenesinvestigadorasesenderechoycienciasblog.wordpress. $\mathrm{com} /$

Recalde, M. (2015). El modelo sindical argentino. Régimen jurídico. Buenos Aires: Editorial Eduvim.

Sarrabayrouse, E. (2015). El derecho penal del primer peronismo y los fusilamientos de junio de 1956. Revista de Historia del Derecho, 50, 131-226. Recuperado de http://www.scielo.org.ar/pdf/rhd/n50/n50a05.pdf

Sowter, L. (2016). La experiencia del Congreso de la Productividad y la política de la cooperación económica durante el peronismo. Revista Temas y Debates, 32, 135-154. Recuperado de http://www.scielo.org.ar/pdf/tede/n32/n 32a07.pdf

Stagnaro, A. (2017). Y nació un derecho. Los tribunales del trabajo en la provincia de Buenos Aires. Buenos Aires: Editorial Biblós.

Vuletich, E. (1955). Empresarios y obreros unidos en un solo objetivo. Hechos e Ideas, 129.

\section{Notas}

1 Becario Doctoral UBACyT. Miembro del Proyecto UBACyT: "La reforma constitucional argentina de 1949: alcances del constitucionalismo social argentino en perspectiva transnacional" a cargo de la Dra. Leticia J. Vita. Docente de la Facultad de Derecho, Universidad de Buenos Aires.

2 Miembro del Proyecto UBACyT: "La reforma constitucional argentina de 1949: alcances del constitucionalismo social argentino en perspectiva transnacional" a cargo de la Dra. Leticia J. Vita. Docente de la Facultad de Derecho, Universidad de Buenos Aires. 
3 Cabría mencionar, cuanto menos, otro subsector específico del peronismo conformado por los diputados José Alonso, Ángel Miel Asquía, Aimar Balbi, Pedro Otero, Armando Vergara y Ernesto Carreras, quienes presentaron un proyecto independiente de la versión oficial. Contaba de solo seis artículos y se centraba en la obligatoriedad de los convenios colectivos para todos los empleadores y trabajadores comprendidos en la categoría profesional y dentro de la zona de aplicación de que se tratara. Mantenía el carácter de "mediador" del Ministerio de Trabajo en la negociación colectiva y la personería gremial de las asociaciones sindicales como requisito para la firma de acuerdos.

4 Para una bibliografía complementaria sobre el "modelo sindical argentino" como categoría analítica, ver Barattini (2015). Respecto a las características que lo conforman ver, entre otros, Abós (1989), Goldin (2013) y Recalde (2015).

5 Paralelamente, el "proceso de conformación de un nuevo campo académico" (Palacio, 2013) que estaba atravesando el derecho del trabajo, y que culmina con su completa autonomización académica y jurisdiccional, se encuentra avanzado en esta época (Palacio, 2018; Stagnaro, 2017). Sin embargo, la convivencia poco pacífica de la nueva jurisprudencia de la Justicia del Trabajo, como así también las disputas de jurisdicción con el fuero civil al momento de decidir sobre contratos individuales y convenios colectivos de trabajo, son consideradas motivaciones para la sanción de la legislación que nos ocupa (Palacio, 2018). Este argumento, que también se halla en las causales de la sanción de una nueva Constitución, prueba la resistencia todavía existente de ciertos elementos del sistema político al proceso peronista. Tal era la necesidad de una homogeneización de la normativa, que la oposición parlamentaria la cita como una de las razones fundamentales para la sanción de la ley, lo que motiva la aprobación en general del proyecto por parte del bloque radical. Ver la intervención del diputado Marcó (Diario de Sesiones de la Cámara de Diputados, 1953, p. 1761).

6 Otros dirigentes obreros, entre los que podemos contar a Adolfo Lanfossi (dirigente de La Fraternidad y diputado por Buenos Aires), Adolfo Pallanza (dirigente del Sindicato Unidos Portuarios Argentinos y diputado por Santa Fe), Hilario Salvo (dirigente de la Unión Obrera Metalúrgica y diputado por Buenos Aires), Silverio Moreno (dirigente de La Fraternidad y diputado por Córdoba) y José Tesorieri (dirigente de la Asociación de Trabajadores del Estado y diputado por Buenos Aires), si bien también realizan aportes, éstos son reducidos o no son relevantes para la discusión general o particular.

7 Los senadores intervinientes fueron Paulino Herrera, representante de San Juan, Antonio Correa, representante de Tucumán, Ilda Pineda de Molins, representante de Buenos Aires y Juan Antonio Ferrari, representante de La Pampa.

8 También ratificado por la ley 12.921 .

9 El corporativismo influyó largamente sobre el diseño del sistema legal peronista en su etapa más prolífera, que abarca las primeras acciones de la Secretaría de Trabajo y Previsión, hasta la Constitución de 1949. A la lectura y análisis de las normas o la conocida admiración de Perón por el sistema italiano puede agregarse la presencia de funcionarios técnicos muy comprometidos con estas ideas, como José Figuerola. En términos de Herrera (2014), ciertos integrantes del gobierno aspiraban a constituir "un mecanismo corporativista purificado de las experiencias históricas" del fascismo (p. 401).

10 Asimilables a las conocidas actualmente como asociaciones sindicales "simplemente inscriptas" y caracterizadas por no poder negociar colectivamente en aquellos ámbitos donde otra asociación detente la personería gremial.

11 El día 25 de agosto de 1944, siendo ya Secretario de Trabajo y Previsión, Perón ofreció su célebre (e igualmente criticado) discurso en la Bolsa de Comercio de Buenos Aires en el que, entre otras cuestiones, advierte sobre la amenaza "extranjera" comunista y una posible huelga general que desestabilizara al gobierno. Por otro lado, la dependencia bajo su dirección buscaría una solución pacífica del conflicto, para intentar evitar así una salida radicalizada. Ver, al respecto, Altamirano (2007).

12 José Ber Gelbard (fundador de la Confederación General Económica), en el discurso inaugural del Congreso de 1955 expresó que era razonable pedir que las comisiones internas y delegados gremiales contribuyeran a consolidar el desenvolvimiento normal de la empresa y a la marcha de la productividad. Tampoco consideró aceptable que "el delegado obrero toque un silbato en una fábrica y la paralice. No hay razón valedera que pueda invocarse, y mucho menos cuando amparan a obreros y empresarios leyes que figuran a la vanguardia de las que rigen en los países más adelantados del mundo" (Ber Gelbard, 1955, p. 280). El mismo año, Eduardo Vuletich (Secretario General de la CGT), en una postura opuesta, decía que la productividad no se daría a través de un "aumento incontrolado de trabajo que pudiera comprometer las conquistas logradas" (Vuletich, 1955, p. 17)

13 Las problemáticas derivadas de este concepto básico, que abordaremos en los siguientes apartados, son particularmente la intervención del Estado en la negociación (homologación), la ultraactividad del convenio y la cuota de solidaridad.

14 Explica Mugnolo (2014): "la representación, que desde el derecho civil se limita a la capacidad para actuar en nombre de otro en lo laboral resulta insuficiente debiéndose apelar al fenómeno de representatividad por ser este más amplio en cuanto a la capacidad de contener a todos los individuos destinatarios de los resultados de las acciones contractuales emprendidas por el sujeto colectivo representante" (p. 178).

15 En lo que respecta a la parte empleadora, el peronismo logrará hacia finales de 1953 la sanción de la ley 14.295 de asociaciones sindicales de empleadores, luego derogada por el golpe de Estado de 1955. 
16 El convenio 87 sobre la libertad sindical y protección del derecho de sindicación fue ratificado por nuestro país a principios de 1960 (durante el gobierno de Frondizi) y el convenio 98 sobre el derecho de sindicación y de negociación colectiva fue ratificado en septiembre de 1956 (durante el gobierno de facto de Aramburu). La laxitud en torno a los requisitos que se establecen para la constitución de organizaciones sindicales y las disposiciones tendientes a lograr un Estado no intervencionista en la acción sindical entran en contradicción con algunas características del "modelo sindical argentino" como el mecanismo de homologación.

17 El decreto-ley es mencionado, entre otros, por el diputado Weidmann en su intervención (Diario de Sesiones de la Cámara de Diputados, 1953, p. 1770). No existía unanimidad respecto a su vigencia y aplicabilidad. En concreto, si bien el decreto nunca fue legalizado por el Congreso, la Corte Suprema de Justicia de la Nación lo declaró válido en el caso "Egidio Ziella c. Smirglio Hnos.", de 1947. Para un desarrollo más exhaustivo, ver Sarrabayrouse (2015).

18 “¿De qué valen muchos sindicatos que congreguen un número reducido de obreros? (...) Interesa una clase obrera unida, disciplinada, consciente de su misión, que sepa defender sus intereses, y eso lo estamos realizando en la República Argentina" (Diario de Sesiones de la Cámara de Diputados, 1953, p. 1806).

19 El diputado cita una larga lista de federaciones y sindicatos intervenidos por el gobierno peronista (Diario de Sesiones de la Cámara de Diputados, 1953, p. 1801).

20 Las que siguen los trazos gruesos del sistema de asociaciones sindicales diseñado por el peronismo (personería gremial, régimen de prerrogativas exclusivas, entre otros).

21 OIT (2008), Observación individual sobre el Convenio sobre la libertad sindical y la protección del derecho de sindicación, 1948 (núm. 87), Argentina (ratificación: 1960), citado por la Corte Suprema de Justicia de la Nación en el fallo "Asociación de Trabajadores del Estado c. Ministerio de Trabajo" (2008).

22 Los artículos 41, inc. a, 52 y 31 inc. a de la ley 23.551 fueron declarados inconstitucionales en los fallos "Asociación de Trabajadores del Estado c. Ministerio de Trabajo" (11/11/2008), "Rossi, Adriana María c. Estado Nacional - Armada Argentina" (09/12/2009) y "Recurso de hecho deducido por la Asociación de Trabajadores del Estado en la causa Asociación de Trabajadores del Estado s. acción de inconstitucionalidad” (18/06/2013), respectivamente. Son artículos importantes para el sistema de derechos exclusivos concedido a la asociación más representativa, relativos a protección de delegados, dirigentes gremiales y la defensa de los intereses colectivos profesionales.

23 Respecto de la autoridad de aplicación, la mencionada ley 12.921, también ratificó el decreto-ley 21.877/44 modificatorio de la ley 11.570 de 1929 . Este conjunto de normas establecía el procedimiento para las infracciones a las leyes del trabajo y las penalidades a establecer a quienes obstaculizaran la acción de la Secretaría de Trabajo y Previsión. Entre los múltiples atributos consagrados a la autoridad laboral se encontraban el establecimiento de multas y clausuras, realizar allanamientos sin autorización judicial previa, ordenar arrestos, utilizar a las fuerzas policiales y bloquear el derecho de peticionar.

24 De acuerdo a la intervención del diputado se celebraron 1.330 convenios colectivos, y fueron escasos los sectores no convencionalizados.

25 Actualmente esta técnica legal, que continúa vigente en el sistema argentino, se realiza considerando y comparando cada institución regulada por el convenio, contra la ley mínima protectoria. Es conocida como "conglobamiento por instituciones". Para un mayor desarrollo, ver Goldin (2013).

26 Cierta doctrina jurídica es crítica a la solución argentina; plantea que este sistema limita el conjunto negocial e impide a los trabajadores el libre intercambio de determinados derechos y obligaciones, por el carácter inescindible del convenio colectivo y de las instituciones que lo componen. Ver Mugnolo (2014).

27 Una situación similar se dio en el año 1975 durante el gobierno de María Estela Martínez de Perón. Ver Elías (2007).

28 Para ahondar en la crítica jurídica a las cuotas de solidaridad, ver Mugnolo (2005).

$29 \mathrm{Al}$ respecto, tal como señaláramos, los fallos de la Corte Suprema citados se respaldan en observaciones de organismos internacionales que no realizan una impugnación general al sistema teniendo presente la opinión de las representaciones gremiales nacionales, sino que sugieren modificaciones que tienden a limitar los privilegios. 